\title{
Influência da inteligência competitiva em processos decisórios no ciclo de vida das organizações
}

José Márcio de Castro

Doutor em administração/USP.

E-mail: josemarcio@pucminas.br

Paulo Gustavo Frankilin de Abreu

Mestrando em administração/Programa de Mestrado em Administração da Pontifícia Universidade Católica de Minas Gerais. E-mail: pgfa@uol.com.br

\begin{abstract}
Resumo
$\mathrm{O}$ artigo analisa como o sistema de inteligência competitiva (IC) afeta o processo decisório, no ciclo de vida das organizações. Busca evidenciar como a IC pode contribuir para que uma organização mantenha a qualidade de suas decisões ao longo do tempo, a partir da redução dos pontos cegos e da constante revisão dos fatores do ambiente externo que influenciam no processo decisório. A pesquisa é de natureza quantitativa, e os dados foram coletados a partir de um questionário aplicado aos associados da SCIP ${ }^{1}$ (Society of Competitive Intelligence Professionals), sediada nos EUA. Os resultados apontam para um importante papel da área de IC como um instrumento na reversão da tendência natural de aumento dos pontos cegos no ciclo de vida da organização.
\end{abstract}

\section{Palavras-chave}

Ciclo de vida das organizações. Inteligência competitiva. Processos decisórios. Pontos cegos.

The influence of competitive intelligence upon the decisive process along the life cycle of the organization

\begin{abstract}
The article discusses how the intelligence competitive system affects the organizational decision-making process. The article searches to demonstrate how competitive intelligence may contribute to an organization to keep the quality of its decision-making process through the reduction of these blind points and the permanent review of the external environment factors that affect the decision-making process The data were collected from a survey carried out at the SCIP (Society of Competitive Intelligence Professionals). The results suggest that the intelligence competitive area has an important role for transforming the environmental monitoring processes into a means to reverse the increasing of blind points at the organization's cycle life.
\end{abstract}

\section{Keywords}

Competitive intelligence. Environment. Decision-making process.

\section{INTRODUÇÃO}

O objetivo deste artigo foi analisar como a inteligência competitiva (IC) pode contribuir para que uma organização mantenha a qualidade do processo decisório, ao longo de seu desenvolvimento, reduzindo os pontos cegos em relação ao ambiente. Segundo a Society of Competitive Intelligence Professionals (SCIP), entidade que representa os profissionais de inteligência competitiva (IC), esta atividade pode ser entendida como

(...) um programa sistemático e ético de coleta, análise, disseminação e gerenciamento das informações sobre o ambiente externo, que podem afetar os planos, as decisões e a operação da organização (SCIP, 2004).

Trata-se de conceito bastante amplo que reflete a diversidade e a variedade das abordagens que têm surgido nesta área, sendo que a IC tem sido utilizada para suportar decisões táticas e estratégicas em todas as áreas funcionais de uma organização.

Durante o ciclo de vida das organizações, o processo decisório sofre transformações que por vezes podem leválas a uma situação de insolvência. Nesses termos, geralmente, uma organização que se encontra no estágio inicial de suas operações tem, na incerteza em relação ao ambiente competitivo, a principal dificuldade a ser enfrentada no processo de tomada de decisões. Fatores como a inexperiência dos gestores ou as dificuldades de interação com o ambiente externo fazem com que a organização, nesse estágio de desenvolvimento, encontre muitas dúvidas para avaliar o comportamento dos principais atores deste ambiente, bem como a interferência que podem exercer sobre a organização.

À medida que a organização se desenvolve e atinge a maturidade, o processo decisório tende a apresentar certa regularidade e previsibilidade provenientes do histórico das decisões anteriores, do maior conhecimento sobre o comportamento dos atores do ambiente externo, da padronização dos processos e do fluxo de informação dentro da organização, dentre outros fatores. Nesse momento, a convicção a respeito do ambiente 
competitivo, entendida aqui como uma crença firme baseada em razões íntimas em relação ao estado de algum evento do ambiente externo, tende a predominar no processo decisório, podendo levar, inclusive, a uma redução na importância que os gerentes atribuem a determinadas informações que vêm do ambiente.

Dessa forma, os pontos cegos ocorrem quando há um descolamento entre a percepção que se tem sobre o ambiente competitivo e o que está realmente acontecendo, e geralmente isso é mais intenso nas organizações em sua fase inicial de desenvolvimento, em razão do elevado nível de incerteza. Entretanto, o mesmo fenômeno pode ocorrer também nas organizações que já atingiram a plenitude do desenvolvimento, desta vez, devido ao elevado nível de certeza que os decisores passam a apresentar em virtude da convicção de que têm controle sobre o mesmo ambiente.

Segundo Gilad (2003), uma das principais funções da IC é evitar que a empresa crie pontos cegos, ou seja, que ocorra a supremacia da convicção interna sobre os fatos e dados coletados do ambiente, convicção esta que pode levar a julgamentos inadequados e conduzir a decisões erradas, afetando o desempenho final da organização. Pretende-se responder à seguinte questão: Como a inteligência competitiva pode auxiliar os gestores na redução dos pontos cegos e, conseqüentemente, contribuir para a otimização dos processos de tomada de decisão nas organizações?

Na primeira parte do artigo, na revisão da literatura, é feita uma discussão sobre o processo de tomada de decisão, os limites da racionalidade do gestor e os fatores que contribuem para aumentar a ocorrência dos pontos cegos, principalmente, nos primeiros estágios da organização e, posteriormente, na sua plenitude. Em seguida, discute-se o papel da inteligência competitiva no monitoramento ambiental e sua atuação na redução da dissonância cognitiva.

Após a revisão da literatura, são descritas a metodologia, bem como a população da pesquisa, o método de coleta e análise de dados. Em seguida, discutem-se os resultados e as conclusões da pesquisa.

\section{REVISÃO DA LITERATURA}

\section{Os processos decisórios e o risco da ocorrência dos pontos cegos}

Dentre as principais atividades dos executivos, a tomada de decisões aparece como a mais relevante e toma grande parte do tempo e da energia dos mesmos. Um dos momentos mais importantes do processo decisório se refere à redução da incerteza a ele relacionado, o que, por sua vez, só é alcançado por meio de um esforço deliberado no sentido de se ampliar a compreensão acerca da principal fonte de incerteza: o ambiente competitivo.

Segundo Cyert e March (1992), a informação sobre o ambiente competitivo não é disponibilizada sem dispêndio, e os recursos necessários para obtê-la concorrem com os recursos direcionados às outras atividades da organização. Deste modo, tão importante quanto ser capaz de entender o ambiente competitivo da melhor maneira possível, é se estruturar para fazê-lo de maneira eficiente. Segundo esses autores, os fatores que mais afetam a capacidade de uma organização no sentido de tomar decisões, a partir do entendimento do ambiente externo, são basicamente os seguintes: a) a utilização, pela organização, de mecanismos para contornar a incerteza ambiental; b) a manutenção da estrutura de poder já consolidada dentro da organização; c) sua capacidade de coletar, armazenar e utilizar a informação. Detalharemos cada um desses fatores nos itens seguintes.

Com relação ao primeiro ponto, os padrões específicos de procedimentos operacionais (Pepos) - que se consolidam mediante as regras de execução de tarefas, registros e relatórios recorrentes, regras de manuseio da informação e planos de implantação e controle da estratégia escolhida - são mecanismos importantes para contornar a incerteza ambiental. Desta forma, soluções referendadas pelos Pepos são preferidas, em relação às soluções inovadoras, fazendo com que as decisões tomadas pela organização ocorram dentro de um padrão de normalidade. Isso faz com que decisões passadas que tenham apresentado resultados satisfatórios sejam preferidas às novas.

Outro ponto relevante nesse aspecto é que a tomada de decisão é feita de acordo com a gravidade e a ordem do surgimento dos problemas. Os indicadores do dia-a-dia prevalecem sobre os de longo prazo. Em parte, isto ocorre porque cada área da organização tende a olhar para os impactos em seus próprios objetivos, na hora de tomar uma decisão.

Por último, a negociação com os participantes do ambiente externo também é vista como sendo uma forma de se evitar a incerteza. Dessa maneira, existe uma tendência de se estabelecerem práticas comerciais e de conduta com os concorrentes, parceiros, dentre outros (por meio de associações de classe, jornais especializados, 
contatos pessoais). Um exemplo típico dessas relações são os acordos sindicais que costumam ser negociados em nível da categoria, de forma que o reajuste salarial é aplicado a todas as organizações de determinado segmento.

Também relevante no entendimento dos fatores que afetam a capacidade da organização de tomar decisões é a manutenção da coalizão de poder que ocorre por meio de uma constante disputa entre os departamentos e setores pela definição dos objetivos da organização. Como essa estrutura de poder afeta a capacidade da organização, o conflito é, por sua vez, resolvido pela delegação, de forma que cada área se responsabilize pelo próprio objetivo, o que permite que uma pessoa cuide de determinado grupo de problemas ou de uma parte do ambiente externo, por uma considerável gama de regras para delinear a decisão e, finalmente, pelo ordenamento dos objetivos de forma a resolvê-los um de cada vez.

O monitoramento ambiental é apenas um dos fatores considerados no processo de tomada de decisão. No entanto, a estrutura de poder interdepartamental interfere na definição de quais aspectos do ambiente serão privilegiados, uma vez que as diferentes áreas da organização atribuem valores diferentes aos segmentos externos. Assim, dependendo do balanceamento da coalizão de poder que ocorre entre os departamentos, um aspecto do ambiente pode se sobrepor a outro. Além disto, se a organização tiver presenciado uma história recente de sucesso, em determinado aspecto de suas operações, as ações tenderão a ser, em grande parte, direcionadas por ações e procedimentos passados. A atividade de monitoramento aqui tem importante papel, no sentido de levar a organização a reavaliar permanentemente seu posicionamento competitivo e seus processos internos.

A sobrevivência a longo prazo de uma organização depende em grande parte de sua capacidade de desenvolver mecanismos que possibilitem a adequada capacidade de previsão do ambiente externo, de maneira que ela possa se posicionar e assumir riscos calculados. Entretanto, ao longo de seu processo de crescimento e amadurecimento, surge a necessidade de delegar poderes e dividir responsabilidades, para implementação da estrutura mais adequada para suportar este processo. À medida que se torna mais diferenciada e diversificada, a estrutura tende a se cristalizar, funcionando de acordo com normas de conduta e procedimentos que foram sendo construídos desde o início das atividades da organização. Tais procedimentos, formais e informais, tendem a conduzir as ações e reações da organização também em relação ao ambiente. É fundamental, portanto, que a organização desenvolva capacidades internas para detectar as mudanças no ambiente externo, de modo a estar reavaliando os procedimentos internos e adequando a estrutura organizacional às condições impostas por este ambiente (ADIZES, 2004). A discussão entre a necessidade de se ajustar à estrutura para atender à estratégia, que, por sua vez, é definida em função do ambiente, não é recente e foi muito bem colocada por Chandler (1998), já na década de 60.

Assim como os Pepos, os demais mecanismos utilizados pela organização durante o processo decisório - tais como os artifícios utilizados para evitar a incerteza, a coalizão de poder, as normas e procedimentos internos, bem como o foco de monitoramento do ambiente externo e as formas de executá-lo - podem ser considerados fatores cristalizadores das decisões (FCDs). Tais fatores, ao mesmo tempo que dão solidez e agilidade ao processo decisório da organização, à medida que eles se consolidam ao longo de uma trajetória de crescimento da organização, causam-lhe, também, rigidez.

Todos os aspectos aqui discutidos buscam dar uma idéia da complexidade do processo decisório dentro de uma organização. Ao longo do tempo, os fatores cristalizadores das decisões tendem a aumentar à medida que a organização considera que já passou pela maioria das situações a ela apresentadas, em razão das variações do ambiente externo. No limite, pode haver uma norma ou um procedimento, seja ele formal ou informal, para todas as situações apresentadas pelo ambiente, de forma que a organização sabe, a priori, quais fatores externos e internos devem ser levados em consideração para responder a cada situação.

Embora se possa argüir pela racionalidade do processo decisório, quando supostamente os decisores fariam completa avaliação das variáveis envolvidas em determinado problema e de todas as implicações de suas escolhas, Simon (1995) claramente demonstrou as limitações cognitivas da racionalidade. Três fatores foram mencionados por ele como especialmente limitadores do processo decisório. $O$ primeiro diz respeito ao problema de acesso às informações. Para que uma decisão seja racional, requer-se conhecer as conseqüências de todas as opções disponíveis. Entretanto, em virtude da fragmentação das informações, parece pouco provável que se obtenham todas as informações necessárias ao encaminhamento do problema. Ou seja, os indivíduos nunca terão perfeito conhecimento de todas as variáveis 
ambientais que podem influenciar determinada decisão. Em segundo lugar, não é possível prever todas as influências de uma decisão sobre as variáveis ambientais, constituindo a imaginação do decisor um rico manancial para suprir esta lacuna. Em terceiro lugar, não é possível levar em conta todas as alternativas possíveis quando se toma uma decisão, mas apenas parte delas, e a escolha de uma opção pode significar a renúncia de outra, o que não é adequadamente considerado.

Em um contexto de racionalidade limitada, Simon (1997) conclui que não existem decisões perfeitas, uma vez que elas se limitam às opções apresentadas. Portanto, entende-se que o comportamento administrativo não é maximizante, mas satisfatório. Como bem enfatizou Simon (1959, p. 267), “(...) Enquanto o futuro não pode determinar o presente, expectativas sobre o futuro podem e, efetivamente, o determinam." Fica claro, assim, que as decisões dependem não só da interpretação da organização quanto ao presente, mas também da interpretação das expectativas em relação ao futuro, colocadas tanto pela organização, quanto pelos outros agentes econômicos que compõem o ambiente.

Na verdade, um dos elementos importantes no processo de mapeamento ambiental consiste em procurar entender como outros agentes econômicos percebem a si mesmos e ao ambiente externo. Uma forma que o decisor tem de avaliar se sua interpretação do ambiente real é adequada consiste em aproximar a imagem que ele construiu daquela apresentada por outros agentes econômicos. Quanto mais próximas forem tais imagens, maior a segurança de que a interpretação estará adequada e corresponde a uma imagem "real" do ambiente. Quando informações são omitidas ou distorcidas, a percepção dos indivíduos certamente é comprometida. Isso se agrava, uma vez que os fatores cristalizadores das decisões interferem na formação dessa percepção, por definirem como esta visão do ambiente será construída. Aguilar (1967) observa que os gestores dedicam boa parte do tempo à atividade de entender o que está ocorrendo com o ambiente externo. A atividade de monitoramento do ambiente provê suporte ao executivo para definir os objetivos organizacionais, para buscar alternativas que possibilitem atingir esses objetivos e para escolher dentre as diversas alternativas apresentadas.

Nesse processo, as decisões se enquadram em, basicamente, duas classificações: as rotineiras (ou recorrentes) e as não-recorrentes. As que se enquadram na primeira classificação são, geralmente, relacionadas às decisões administrativas e operacionais, para as quais as organizações desenvolvem mecanismos que tornam o processo decisório praticamente automático. As decisões não-recorrentes, contudo, são mais difíceis, pois as atividades de entendimento do ambiente são mais complexas e geralmente não se tem uma idéia precisa acerca das informações mais relevantes para uma decisão, nem estão disponíveis da forma como se desejaria, pois se referem a problemas novos (AGUILAR, 1967).

Utilizando-se a tipologia de decisão anteriormente mencionada, os fatores cristalizadores das decisões costumam prevalecer nas decisões rotineiras, tendendo a aumentar ao longo do tempo, à medida que uma organização mais madura já enfrentou, por várias vezes, grande diversidade de situações derivadas de variações do ambiente externo. De modo semelhante, Adizes (2004) ressalta que as áreas funcionais de uma organização possuem atividade e foco específicos, e, quando mescladas, o foco da atividade de curto prazo tende a preponderar sobre a de longo prazo. Para Cyert e March (1992), o mesmo fenômeno pode ser explicado pelo fato de que as organizações tendem a resolver um problema de cada vez e, como os problemas de curto prazo são, por natureza, mais urgentes do que os de longo prazo, a tendência é que os de longo prazo fiquem sempre relegados ao segundo plano. Uma visão geral das áreas funcionais da empresa foi apresentada por Adizes (2004) e mostra a orientação temporal de algumas dessas áreas, como mostrado no quadro 1.

De maneira geral, os fatores cristalizadores de decisões tendem a se consolidar com maior rapidez nas áreas que priorizam atividades de curto prazo. Contribui também para isto o fato de que os processos decisórios das atividades de curto prazo tendem a recorrer menos a

QUADRO 1

Distribuição típica do foco de atenção das áreas funcionais

\begin{tabular}{c|c|c}
\hline $\begin{array}{c}\text { Foco no curto } \\
\text { prazo (presente) }\end{array}$ & Intermediário & $\begin{array}{c}\text { Foco no longo prazo } \\
\text { (futuro) }\end{array}$ \\
\hline Vendas & & Marketing \\
\hline Produção & & Engenharia \\
\hline Pessoal & & $\begin{array}{c}\text { Pecursos Humanos } \\
\text { Desenvolvimento }\end{array}$ \\
\hline & Contabilidade & Finanças \\
\hline & $\begin{array}{c}\text { Tecnologia da } \\
\text { Informação }\end{array}$ & \\
\hline & Jurídico & \\
\hline
\end{tabular}

Fonte: adaptado de Adizes (2004, p. 242). 
informações do ambiente externo, já que se baseiam em regras de decisão já consolidadas pelos FCDs.

Nesses termos, Adizes (2004) enfatiza a existência de duas situações que concorrem para aumentar o risco da ocorrência dos pontos cegos em relação ao ambiente externo. A primeira, na fase de infância da organização, há geralmente elevado grau de dependência em relação à energia e a visão do fundador. As organizações são criadas, muitas vezes, a partir de uma nova idéia ou de uma nova abordagem, muitas vezes iniciada ao acaso a partir da prática ou da repetição de outro modelo de negócio bemsucedido Desta forma, poucas organizações iniciam sua trajetória com um sistema de monitoramento ambiental já construído. Como nesta fase as organizações passam por diversas crises e seu foco é geralmente na estabilização dos processos internos, pode ocorrer que elas sejam surpreendidas por abruptas mudanças no ambiente. Dependendo da amplitude da mudança, a própria sobrevivência da organização pode ser ameaçada.

A segunda, quando a organização atinge a plenitude, já com seus processos consolidados, mais bem posicionada competitivamente e com bom desempenho de vendas, ela pode começar a apresentar sinais de declínio. Nessa situação, o sistema de monitoramento ambiental pode não ser forte o suficiente para convencer a organização que o ambiente externo mudou e que é necessário adaptar-se à nova realidade. Seu elevado padrão de confiança nos padrões passados, a sensação de segurança proporcionada pelo sucesso, o baixo senso de urgência e a excessiva confiança nos dados factuais e mensuráveis podem levar a organização a reduzir seu nível de atenção em relação ao ambiente que a cerca. Ambas as situações podem ser visualizadas no gráfico 1, ao lado.

\section{O relacionamento entre a IC e a ocorrência dos pontos cegos no ciclo de vida das organizações}

O papel da IC em relação à ocorrência dos pontos cegos nas organizações

Além de dar suporte às decisões estratégicas e táticas, a atividade de IC pode ser utilizada para auxiliar uma organização a diagnosticar sua posição competitiva. Para Prescott (2004), contudo, as principais funções da área de IC estão relacionadas a oferecer suporte aos sistemas administrativos, participando ativamente das decisões em todos os níveis. Gilad (2003) entende que uma das principais funções da inteligência competitiva é evitar que a organização crie pontos cegos, ou seja, que ocorra a supremacia da convicção interna sobre os fatos e dados

\section{GRÁFICO 1}

Relação entre o risco de ocorrência dos pontos cegos e o ciclo de vida da organização

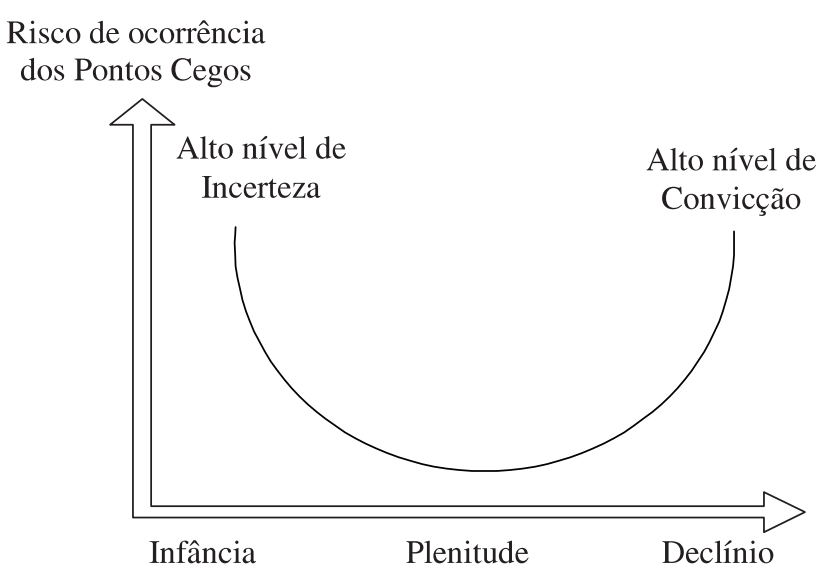

Ciclo de Vida da Organização

Fonte: elaborado pelos autores.

coletados do ambiente externo. A convicção leva a julgamentos que podem revelar-se inadequados e conduzir a decisões erradas, afetando o desempenho final da organização.

A seqüência dos acontecimentos, segundo o autor, ocorre da seguinte forma:

a) a organização alcança uma posição competitiva confortável;

b) a liderança corporativa é reconhecida por ter levado a organização a esta posição;

c) como conseqüência, a liderança torna-se convicta de suas posições, estratégias e de sua visão sobre o caminho que a organização deve seguir. A organização se torna "arrogante";

d) a liderança se identifica publicamente com suas visões e estratégias, ou seja, a estratégia atual não pode mais ser dissociada da liderança que a implementou;

e) a liderança, consciente ou inconscientemente, toma medidas para evitar que o corpo gerencial questione suas posições (ego elevado dos principais executivos);

f) as convicções começam a prevalecer sobre os dados e fatos que indicam mudança no ambiente competitivo;

g) ocorre um hiato entre as convicções dos executivos e a realidade do ambiente competitivo que está sempre mudando. Surgem então os pontos cegos; 
h) a organização passa a tomar decisões inadequadas;

i) a organização é surpreendida por inesperada queda de resultados ou de posição competitiva;

j) se ainda houver tempo, a organização começa a tomar ações corretivas (GILAD, 2003).

Gilad (2003) lembra que, geralmente, as organizações estão bem preparadas para monitorar o risco operacional, o risco financeiro, mas não o risco estratégico, que ocorre quando há desalinhamento entre a estratégia e o ambiente competitivo. Infere-se, daí, que um alto grau de incerteza é tão perigoso para a sobrevivência da organização quanto um alto grau de convicção a respeito da estratégia que tem sido utilizada. Em artigo publicado sobre gestão do risco estratégico, Gilad (2001) aponta que algumas organizações gastam bilhões para criar novos produtos, mas geralmente se esquecem de defendê-los com um bom sistema de monitoramento de risco estratégico.

gráfico 2 mostra duas situações possíveis. São referenciadas duas empresas que, mesmo tendo iniciado suas atividades ao mesmo tempo, tomaram caminhos diferentes ao longo de sua trajetória.
Na empresa 1, a importância da IC no processo decisório cresceu no mesmo ritmo da consolidação dos fatores cristalizadores de decisões (FCDs), e ela pôde evitar o problema da predominância da convicção no processo decisório. Na empresa 2, a importância dos fatores cristalizadores de decisões (FCDs) no processo decisório é maior do que a IC, de forma que a convicção predomina sobre as mudanças do ambiente competitivo.

O aspecto que desejamos enfatizar é que a maneira como a inteligência competitiva interfere no processo decisório de uma organização parece variar em função do estágio em que organização se encontra em seu ciclo de vida. Se, no estágio inicial das operações, o foco da área de IC deve ser no sentido de diminuir o nível de incerteza que uma organização tem a respeito do ambiente competitivo, na fase mais madura, a IC deve se preocupar em questionar as posições que a organização conquistou perante o ambiente, evitando que entre na fase de envelhecimento. Desenvolver mecanismos para questionar as convicções que uma organização tem a respeito de si mesma e sobre os outros atores do ambiente competitivo consiste, assim, em uma das tarefas mais importantes da IC.

Embora a inteligência competitiva tenha como ponto de partida a identificação dos itens de monitoramento,

\section{GRÁFICO 2}

Trajetórias possíveis de duas empresas ao longo do ciclo de vida, considerando a importância que a IC e os fatores cristalizadores das decisões (FCDs) têm no processo decisório

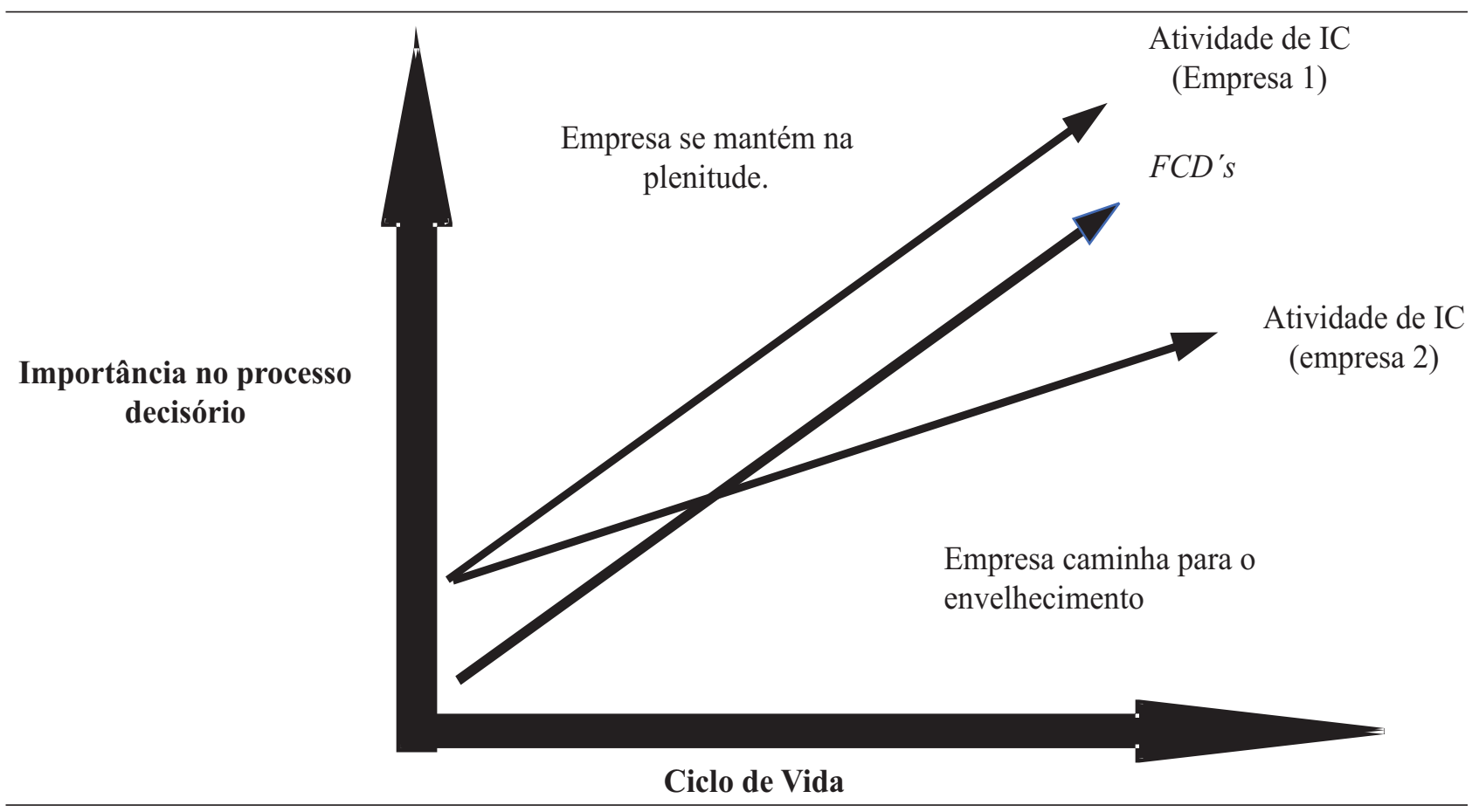

Fonte: elaborado pelos autores. 
outros autores, como Blanco, Caron-Fasan e Lesca (2003), salientam ainda a importância de uma organização se capacitar, até mesmo, em mudanças ambientais que estejam fora do escopo de preocupação pela gerência.

Da mesma forma, uma das atividades mais importantes dos indivíduos responsáveis pela implementação da área de IC na organização consiste em identificar as necessidades de informação para oferecer suporte aos processos decisórios (PRESCOTT, 2004). Também Tyson (2002) recomenda a utilização de instrumentos de pesquisa (questionários, por exemplo) para possibilitar o diagnóstico das necessidades de informação do corpo gerencial. $\mathrm{O}$ autor sugere ainda que a atividade de IC deve dar suporte ao planejamento estratégico, de forma a mantê-lo sempre atualizado acerca das mudanças ambientais, da posição competitiva e de qualquer mudança que afete os "fatores críticos de sucesso" da organização. Desta forma, a organização passa a ter uma estratégia permanentemente atualizada.

Já Herring e Francis (1999) sugerem um processo mais formalizado de levantamento das necessidades de informação, conhecido como Key Intelligence Topic (KIT), como o ponto de partida para a área de IC. O KIT abrange três aspectos: a) suporte a ações e decisões estratégicas; b) identificação de mudança de rumo dos principais atores do ambiente, tais como competidores, governo, fornecedores de tecnologia, dentre outros; c) descrição dos principais atores do ambiente competitivo.

\section{O processo de implantação da IC}

Geralmente, quando uma área de IC inicia suas atividades, o nível de desconhecimento da gerência sobre o ambiente externo é elevado e as informações solicitadas são relativas a dados históricos, orçamentos e outros tipos de informação que podem ser atendidos mediante a consulta a fontes secundárias. Posteriormente, os decisores começam a solicitar informações sobre o presente (como, por exemplo, o posicionamento dos concorrentes), até que, finalmente, as solicitações vão se tornando mais seletivas e mais precisas a respeito do futuro (MCGONAGLE, 2002). De qualquer forma, como acentua Fuld (1988), é sempre relevante informar à gerência sobre mudanças ambientais, mesmo que elas não tenham sido solicitadas e que não sejam requisitos de monitoramento específico da gerência. A construção de itens de monitoramento a partir da identificação dos riscos estratégicos foi uma das contribuições de Gilad (2003) para a área de IC, que passou a monitorar as mudanças potenciais, no mercado ou na indústria, dependendo do grau de vulnerabilidade da organização.

A identificação dos itens a serem utilizados em um processo de monitoramento tem como objetivo principal definir os principais pontos de incerteza dos tomadores de decisão e, a partir daí, transformar dados em inteligência por meio do ciclo da inteligência. Para Ganesh, Miree e Prescott (2003), o ciclo da inteligência é o principal modelo mental utilizado e entendido pela comunidade de inteligência competitiva.

A etapa que antecede o ciclo da informação é a da identificação da informação que se deseja para subsidiar determinada decisão, seja ela rotineira ou não. Existem várias técnicas para se identificar uma informação desejada, e a maioria delas trata de um problema fundamental levantado pela Teoria da Contingência: a questão da equivocidade, que pode ser entendida como a existência de múltiplas e conflituosas interpretações sobre a situação da organização perante o ambiente competitivo (WEICK, 1979; DAFT; MACINTOSH, 1981). O ciclo da inteligência termina quando a informação validada e analisada é entregue ao tomador de decisão, no formato e tempo adequados. Este ciclo se renova quando o usuário da informação retorna ao produtor da informação o nível de consonância obtido com o uso daquela informação.

O processo descrito anteriormente se contrapõe a uma prática bastante comum nas organizações, que é o de repassar as informações da forma como foram captadas no ambiente externo, sem que se faça uma análise da veracidade e da relevância daquela informação para a organização que acaba por introduzir ainda mais incerteza no corpo decisório da organização. $O$ processamento do ciclo de inteligência deve contemplar, basicamente, as seguintes etapas, descritas no quadro 2, a seguir.

A identificação dos itens de monitoramento, que surgem das incertezas com relação ao ambiente, e a transformação dos dados em inteligência endereçam o problema da incerteza na fase de infância de uma organização. Entretanto, à medida que a organização cresce e prospera, os fatores cristalizadores da decisão tendem a preponderar no processo decisório. Deste modo, a área de IC deve ter um procedimento para revisar constantemente os itens de monitoramento, pois estes podem perder o sentido à medida que o ambiente externo se modifica - ou, mesmo, que eles percam a capacidade de identificar uma mudança relevante para a organização. 
QUADRO2

Características das etapas do ciclo de inteligência

\begin{tabular}{|c|c|}
\hline Etapas & Processamento \\
\hline Coleta & $\begin{array}{l}\text { Após estudo das alternativas de fontes } \\
\text { disponíveis, coleta-se a informação. }\end{array}$ \\
\hline Validação & $\begin{array}{l}\text { O processo de validação da informação utiliza, } \\
\text { geralmente, duas técnicas: } \\
\text { - triangulação: cruzamento de informações } \\
\text { provenientes de várias fontes; } \\
\text { - checagem dos fatos: etapa que precede o } \\
\text { surgimento da informação propriamente dita. }\end{array}$ \\
\hline Análise & $\begin{array}{l}\text { Avaliação do impacto da informação para a } \\
\text { posição competitiva da organização. }\end{array}$ \\
\hline Disseminação & $\begin{array}{l}\text { Apresentação das alternativas de ações } \\
\text { disponíveis para a organização e de suas relações } \\
\text { custos versus benefícios, considerando-se: } \\
\text { - as limitações da organização em executá-las; } \\
\text { - a reação mais provável do ambiente a cada } \\
\text { uma delas. }\end{array}$ \\
\hline Realimentação & $\begin{array}{l}\text { Avaliação do usuário final acerca da inteligência } \\
\text { recebida para obtenção de melhorias nos } \\
\text { processos utilizados em cada etapa do ciclo da } \\
\text { informação. Também é nesta fase que o gestor } \\
\text { de inteligência competitiva se preocupa em } \\
\text { reconhecer e validar as pessoas que participaram } \\
\text { do processo. }\end{array}$ \\
\hline
\end{tabular}

Fonte: Abreu (2000).

Como mencionado anteriormente, com freqüência os gestores tendem a atribuir maior importância às informações provenientes do setor onde eles atuam. Para exemplificar, setores tradicionais, como o de siderurgia ou o de vidros, sofreram drasticamente com a entrada de novas tecnologias e novos materiais, como, por exemplo, a substituição das garrafas de vidro pelas garrafas PET, ou a introdução da embalagem tetra pak na indústria de plásticos.

Estes exemplos mostram que ameaças e oportunidades também podem surgir de outros setores ou áreas do conhecimento. $\mathrm{O}$ importante, nestes casos, seria que as organizações afetadas tivessem sido capazes de antever a entrada destas novas tecnologias, por meio da captação de sinais fracos, muito antes de eles se materializarem no mercado. Isto pode ser feito pela captação e tratamento de rumores ou ainda pelas análises de banco de dados de informações, tais como patentes, notícias, estudos acadêmicos, dentre outros. No quadro 3, sintetizamos algumas características dos chamados "sinais fracos".
QUADRO 3

Características dos sinais fracos

\begin{tabular}{|c|c|}
\hline Natureza & Conseqüência para sua utilização \\
\hline Antecipatória & $\begin{array}{l}\text { Sinais fracos estão relacionados a eventos } \\
\text { potenciais futuros que podem afetar a organização. } \\
\text { Eles devem avisar aos gerentes com antecedência } \\
\text { suficiente para que eles esbocem uma reação. } \\
\text { Entretanto, cada sinal fraco não tem muito } \\
\text { significado em si mesmo e é muito difícil relacioná- } \\
\text { lo a decisões imediatas. }\end{array}$ \\
\hline Qualidade & $\begin{array}{l}\text { Sinais fracos não são números com registros ou } \\
\text { extrapolações. Eles são relacionados a eventos } \\
\text { potenciais que ainda não ocorreram e podem nunca } \\
\text { ocorrer. Sinais fracos que nos alertam para o futuro } \\
\text { podem não se constituir em dados quantitativos } \\
\text { ou factuais. }\end{array}$ \\
\hline Ambigüidade & $\begin{array}{l}\text { Sinais fracos não são certezas, mas sim pistas e } \\
\text { traços de informação. Eles podem ser interpretados } \\
\text { de diversas maneiras, sem que haja a possibilidade } \\
\text { de se identificar a interpretação correta ou mesmo } \\
\text { as que não podem ser interpretados.Por isso, não } \\
\text { são fáceis de se capturar. }\end{array}$ \\
\hline Fragmentação & $\begin{array}{l}\text { Sinais fracos são apresentados em forma de } \\
\text { fragmentos que foram pacientemente coletados por } \\
\text { vários rastreadores ambientais. Separadamente, } \\
\text { cada fragmento é insignificante e suspeito e sua } \\
\text { significância só pode ser obtida por meio de um } \\
\text { paciente processo de cruzamento de informações. }\end{array}$ \\
\hline $\begin{array}{l}\text { Diversidade } \\
\text { de forma }\end{array}$ & $\begin{array}{l}\text { Fragmentos de informação podem ser capturados } \\
\text { em qualquer formato, tais como partes de diálogos, } \\
\text { informação eletrônica, mensagens de conferências, } \\
\text { dentre outros. Como não são homogêneas, sua } \\
\text { exploração torna-se muito difícil. }\end{array}$ \\
\hline
\end{tabular}

Fonte: adaptado de Blanco et al (2003).

Com as técnicas de IC, uma organização pode capacitar e motivar seus funcionários a captar sinais fracos e enviálos a uma área dedicada a analisar e validar estas informações, utilizando e construindo significados para informações dispersas entre as várias áreas de uma organização.

\section{METODOLOGIA DA PESQUISA}

\section{Estratégia e método de pesquisa}

Com o objetivo de estudar o papel da IC nos processos decisórios, optou-se pela realização de uma pesquisa do tipo quantitativa, com o uso de questionário aplicado aos profissionais de inteligência competitiva associados 
à SCIP (Society of Competitive Intelligence Professionals), sediada nos EUA.

\section{Unidades de análise da pesquisa}

Dada a sensibilidade das empresas em responder a pesquisas e questionários sobre a maneira pela qual monitoram o ambiente, para Ganesh, Miree e Prescott (2003), os seguintes cuidados devem ser tomados para se obter bom retorno do número de questionários enviados:

- o tópico deve ser interessante para a empresa e para a pessoa que está sendo abordada, e o pesquisador deve ser se comprometer em compartilhar os resultados da pesquisa com os respondentes;

- a abordagem deve ser feita por meio de uma entidade reconhecida pela comunidade de IC (tais como, SCIP e APQC - American Productivity and Quality Center), em função da sua trajetória de trabalho junto aos associados;

- um acordo de confidencialidade para proteger os interesses do investigado e do investigador deve ser assinado antes do envio do questionário.

Nesta pesquisa, procurou-se atender a todas as recomendações citadas anteriormente; entretanto, a questão da confidencialidade das informações foi tratada no próprio corpo do e-mail convite enviado ao público qualificado, uma vez que o pesquisador se comprometeu a não revelar informações individuais dos respondentes.

Dada a necessidade de se obter uma amostra de empresas em diferentes estágios de implantação da atividade de IC, foi necessário aplicar o questionário não só na comunidade de IC brasileira, mas também em uma população na qual a IC já estivesse consolidada há mais tempo. Desta forma, optou-se por fazer uma pesquisa internacional, com foco predominante nos EUA, país onde a atividade de IC já é bastante consolidada nas principais empresas.

Mediante consulta ao cadastro de associados da SCIP, foram selecionados 1.878 especialistas (que se apresentavam como analistas, tomadores de decisão, integradores e construtores de sistema de inteligência competitiva) de um universo total de 2.976, que, potencialmente, poderiam ser qualificados como responsáveis ou co-responsáveis pela gestão do processo de inteligência dentro das respectivas empresas.

\section{A coleta de dados}

A elaboração do instrumento

Para a coleta de dados junto a essa população, foi elaborado um questionário remetido por e-mail sob os auspícios da SCIP.

Os itens abordados e a escala utilizada foram resultantes de pesquisa exploratória em bibliografia especializada, documentos e consultas a especialistas da área de IC. Após a elaboração do instrumento de coleta de dados, foi feito o pré-teste do questionário (eletrônico) junto a um grupo de 30 profissionais em IC, que atuam em empresas brasileiras e norte-americanas. Este processo de preparação que antecedeu a etapa da coleta se deu no segundo semestre de 2004.

Posteriormente, foi feita uma consulta junto a pesquisadores que já realizaram pesquisas a partir da mesma base de cadastro, e decidiu-se pelo atendimento da recomendação de inclusão de duas questões para melhor qualificar o respondente, tendo em vista que:

- a manutenção dos dados cadastrais é, em grande parte, de responsabilidade do próprio associado;

- o próprio associado pode ter se enganado ao informar sua atividade no momento do cadastro.

O questionário utilizado foi uma escala do tipo Likert de 7 (sete) pontos, variando de 1 (nunca) a 7 (sempre).

\section{Estratégia de envio do instrumento de coleta}

Em recente pesquisa feita junto aos associados da SCIP por Qiu (2004), a taxa de retorno ao convite para participar da pesquisa por meio de um questionário eletrônico havia sido de $12,1 \%$. Considerando que a população qualificada desta pesquisa foi de 1.878 pessoas, esperava-se um retorno aproximado de 227 questionários devidamente preenchidos. Entretanto, para aumentar a taxa de retorno e garantir o sucesso da fase de coleta de dados, além de oferecer os resultados parciais do estudo aos participantes, por meio de um relatório preliminar, as seguintes ações foram tomadas para aumentar a credibilidade da pesquisa junto ao público-alvo:

- obteve-se o endereço de e-mail de uma instituição de ensino, para enviar a carta-convite;

- optou-se por divulgar a pesquisa pelo SCIP ON-LINE, jornal eletrônico da SCIP, antes mesmo de se enviar o e-mail ao público qualificado. 
O passo seguinte foi o envio personalizado do convite, mencionando o fato de a chamada para a pesquisa ter sido publicada no jornal eletrônico da SCIP e, também, oferecendo um relatório com os resultados preliminares para aqueles que informassem o respectivo endereço de e-mail, ao final do questionário.

Posteriormente, o convite foi reenviado aos potenciais participantes do público qualificado que ainda não haviam se disponibilizado a responder ao questionário. Isto ocorreu após um mês do envio do primeiro e-mail e quando já se contabilizavam 150 questionários preenchidos. O segundo e-mail foi enviado por dois motivos: a taxa de retorno ainda estava abaixo do esperado e em razão do recebimento de grande número de e-mails automáticos de pessoas que estavam viajando. Ao final da fase de coleta, $227(13,4 \%)$ pessoas efetivamente receberam o convite, abriram o questionário e responderam a todas as questões.

\section{Recepção, triagem e organização dos dados}

Como o público-alvo da pesquisa consistia nos responsáveis ou co-responsáveis pelo sistema de inteligência competitiva de suas respectivas empresas, aplicou-se um filtro para a identificação dos participantes que se enquadravam na população-alvo (tabela 1).

\section{Estratégia de análise dos dados}

Para verificar a relação entre a IC e sua contribuição para a redução dos pontos cegos, foram utilizados os seguintes construtos e variáveis de análise:

\section{a) TEMPO DE EXISTÊNCIA DA IC}

Avalia o tempo de existência da área de IC na empresa. Utilizou-se uma questão aberta para coletar a informação, como segue:

For how many years has the organization you work for had an established CI activity?

\section{b) NÍVEL DE MUDANÇA DOS IM}

Buscou-se avaliar a freqüência de mudança dos itens de monitoramento (IM) referentes ao ambiente externo. Este construto constitui uma proxi da freqüência com que uma organização reavalia seu processo de monitoramento dos fatores considerados mais relevantes no ambiente externo e que, por vezes, influenciam no processo decisório. Uma organização com elevado nível de predominância de fatores cristalizadores de decisão
TABELA 1

Resultados da etapa de coleta de dados

\begin{tabular}{ll|r|r}
\hline \multicolumn{2}{l|}{ Classificação } & Total & \\
\hline$(=)$ & Convites enviados & 1.808 & \\
\hline$(-)$ & $\begin{array}{l}\text { Convites não entregues (endereços de } \\
\text { e-mails incorretos) }\end{array}$ & 119 & \\
\hline$(=)$ & Convites enviados e recebidos & 1.689 & $100,0 \%$ \\
\hline$(-)$ & Não abriram o link para o questionário & 1.224 & $72,5 \%$ \\
\hline$(=)$ & Abriram o link do questionário & 465 & $27,5 \%$ \\
\hline$(-)$ & Não responderam a nenhuma pergunta & 210 & $12,4 \%$ \\
\hline$(=)$ & Começaram a responder ao questionário & 255 & $15,1 \%$ \\
\hline$(-)$ & $\begin{array}{l}\text { Não terminaram de responder ao } \\
\text { questionário }\end{array}$ & 28 & $1,7 \%$ \\
\hline$(=)$ & Responderam a todas as questões & 227 & $13,4 \%$ \\
\hline$(-)$ & $\begin{array}{l}\text { Consultores, estudantes, fornecedores e } \\
\text { outros }\end{array}$ & 50 & $3,0 \%$ \\
\hline$(=)$ & $\begin{array}{l}\text { Responsáveis ou co-responsáveis pela } \\
\text { atividade de IC }\end{array}$ & 177 & $10,5 \%$ \\
\hline
\end{tabular}

Fonte: elaborado pelos autores.

(FCDs) tenderá a apresentar baixos níveis de mudança dos itens de monitoramento, já que ela provavelmente considera que conhece todos os itens a serem monitorados. Esta variável foi mensurada a partir da pergunta a seguir, como dito antes, por meio da escala de Likert variando de 1 (nunca) a 7 (sempre):

How frequently do you need to change the set of variables and issues of the business environment you constantly track?

Empresas que sempre reavaliam os itens de monitoramento referentes ao ambiente externo estão adaptando seus respectivos sistemas de IC às transformações deste mesmo ambiente, permitindo que o processo decisório ocorra a partir de uma leitura mais precisa do que se dá fora da empresa.

\section{c) NÍVEL DE UTILIZAÇÃO DOS SF}

Avalia a freqüência com que os sinais fracos (SF), principalmente aqueles representados pelos rumores e comentários eventualmente captados pelos funcionários da organização, transformam-se em itens de monitoramento. Este construto nos dá uma medida do esforço que a organização faz para evitar a ocorrência dos pontos cegos, bem como a predisposição da gerência em reavaliar as prioridades de monitoramento externo previamente definidas. Esta variável foi mensurada a partir da pergunta a seguir, disposta em uma escala de Likert, variando de 1 (nunca) a 7 (sempre): 
How frequently do some rumors and/or comments, captured from the business environment, turn out to be important issues to be constantly monitored?

Assim sendo, empresas que utilizam com freqüência os sinais fracos captados por toda a organização como insumo para reavaliar constantemente os itens de monitoramento referentes ao ambiente externo diminuem as chances de ocorrência dos pontos cegos.

\section{d) INFLUÊNCIA DOS FCDs}

Para avaliar o nível de influência dos fatores cristalizadores de decisões (FCDs) no processo decisório, utilizouse como proxi uma combinação dos construtos (b) e (c). Assim, a INFLUÊNCIA DOS FCDs se dá pelo inverso da multiplicação dos construtos (b) e (c), ou seja:

\section{INFLUÊNCIA DOS FCDs $=$ 1 (([NÍVEL DE MUDANÇA DOS IM] X [NÍVEL DE UTILIZAÇÃ̃ DOS SF]))}

Deste modo, se, por exemplo, o respondente assinalou que o conjunto de itens de monitoramento está sempre em mudança e que os sinais fracos sempre se transformam em itens de monitoramento, significa que a influência dos FCDs sobre o processo decisório será $1 /(7 \times 7)=$ 0,02 . Isto sugere que existe muito pouca rigidez no processo decisório da empresa, na medida em que, a cada momento, diferentes informações sobre o ambiente externo são consideradas para a tomada de decisão.

\section{DESCRIÇÃO E ANÁLISE DOS DADOS}

Com relação à idade das empresas na qual atuam os profissionais entrevistados pela pesquisa, os dados mostraram que $22 \%$ dos respondentes trabalham em organizações com mais de 100 anos de fundação e somente $13 \%$ atuam em empresas com até 10 anos de existência, como demonstrado no gráfico 3. A média de idade dessas empresas é 59 anos.

Com relação à experiência dos profissionais no processo de implantação e gestão da atividade de IC, como mostra a tabela 2, a seguir, há concentração na faixa de até dois anos de experiência. Possivelmente, os profissionais menos experientes devem se sentir mais motivados a participar deste tipo de pesquisa, já que receberiam relatório com as conclusões preliminares do estudo e devem ter menos restrições quando se trata de passar informações indicadoras do estágio atual da atividade de IC na empresa onde trabalham.

Considerando agora o tempo de existência da atividade de IC (tabela 3), a distribuição de freqüência apresenta um comportamento mais heterogêneo. Nota-se que 25\% das empresas já possuem IC há mais de quatro anos.

\section{GRÁFICO 3}

Pareto da idade das empresas da amostra qualificada

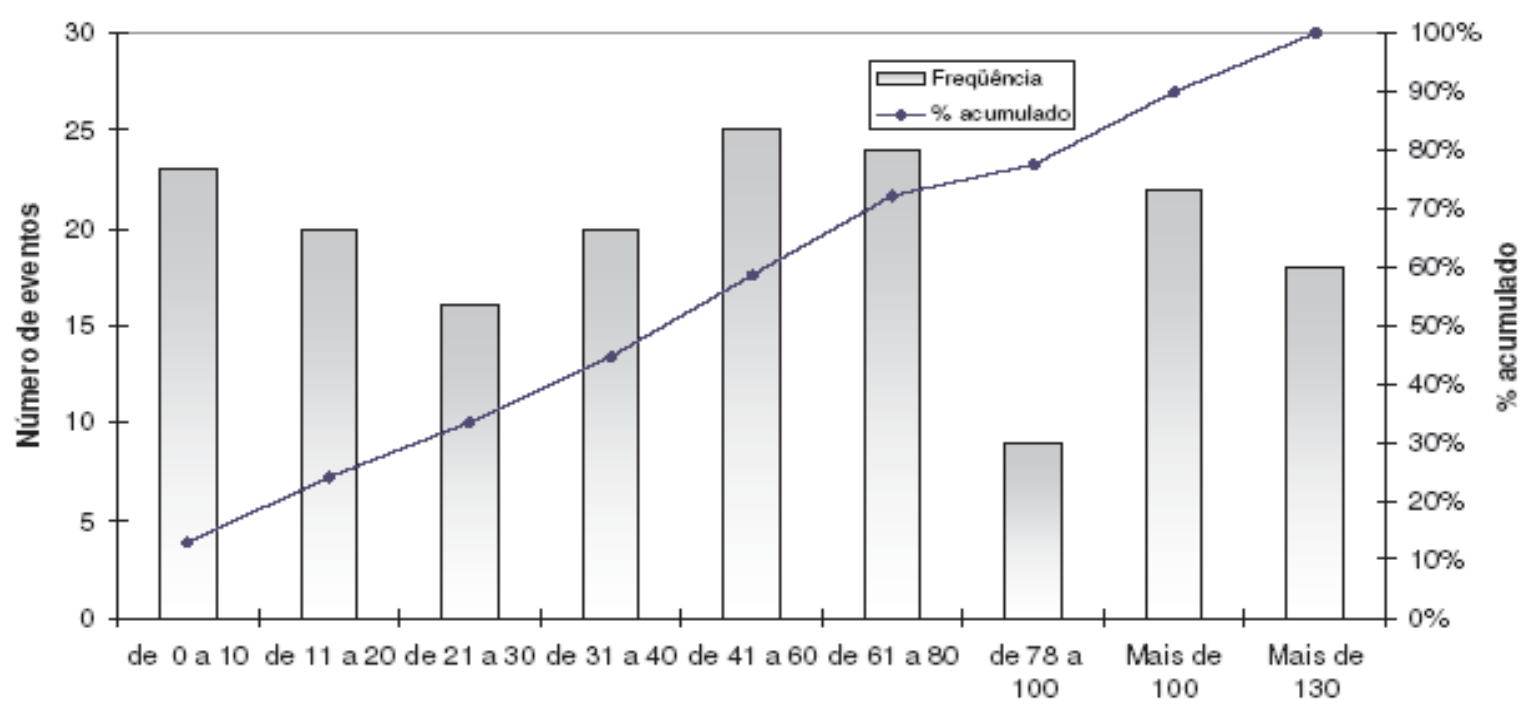

Idade da embresa

Fonte: elaborado pelos autores. 
Quanto ao país de origem dos respondentes, composta pelos 177 responsáveis ou coresponsáveis pela atividade de $\mathrm{IC}$, foram utilizadas para identificação as duas últimas letras do endereço de e-mail. Entretanto, dos 177 respondentes, 31 não deixaram o endereço de e-mail; assim, a origem dos questionários, classificados por país de origem, baseou-se nos 146 respondentes que informaram e-mail e que, portanto, receberam relatório com os resultados parciais do estudo, conforme mostra a tabela 4 . Verifica-se que $77,4 \%$ da amostra qualificada são provenientes de empresas norte-americanas.

Dos 177 respondentes da amostra qualificada, 160 são filiados à SCIP. Desses, $46 \%$ possuem mais de quatro anos de afiliação. Embora a SCIP não seja a única entidade que forneça treinamento formal em IC e divulgue artigos e estudos sobre o assunto aos afiliados, a tabela 5 é um indicador do nível de exposição que os respondentes tiveram às técnicas e abordagens desta atividade.

Para avaliarmos como a área de IC atua no enfraquecimento da influência dos FCDs no processo decisório ao longo do ciclo de vida da organização, mediu-se, primeiramente, o comportamento da influência dos FCDs sobre o processo decisório por meio da média deste construto, em diferentes subgrupos, considerando-se a idade das organizações.

Como visualizado no gráfico 4, a seguir, organizações mais velhas tendem a apresentar aumento da influência dos fatores cristalizadores de decisões nos processos decisórios, refletindo cristalização na maneira pela qual o ambiente externo é monitorado e menor utilização dos sinais fracos como ferramenta de atualização dos itens de monitoramento. Esse aumento da influência dos FCDs no processo decisório faz com que as decisões sejam cada vez mais tomadas de acordo com as normas e procedimentos internos da empresa, bem como a partir dos mesmos fatores do ambiente externo, de forma a aumentar a chance de ocorrência dos pontos cegos.

Entretanto, quando se considera o comportamento das mesmas variáveis, tomando-se apenas as organizações que
TABELA 2

Distribuição de freqüência da experiência dos profissionais em implantação e gestão da atividade de IC

\begin{tabular}{l|c|c|c}
\hline Anos de experiência & Freqüência & $\%$ do Total & $\%$ acumulado \\
\hline Até 2 anos & 71 & $40 \%$ & $40 \%$ \\
Até 4 anos & 27 & $15 \%$ & $55 \%$ \\
Até 8 anos & 48 & $27 \%$ & $82 \%$ \\
Até 16 anos & 27 & $15 \%$ & $98 \%$ \\
Mais de 16 anos & 4 & $2 \%$ & $100 \%$ \\
Total & 177 & $100 \%$ & $0 \%$ \\
\hline
\end{tabular}

Fonte: dados primários da pesquisa.

\section{TABELA 3}

Distribuição de freqüiência do tempo de existência da atividade de inteligência competitiva (IC)

\begin{tabular}{l|c|c|c}
\hline $\begin{array}{l}\text { Anos de existência da } \\
\text { atividade de IC }\end{array}$ & Freqüência & $\%$ do Total & $\%$ Acumulado \\
\hline Até 2 anos & 47 & $27 \%$ & $27 \%$ \\
Até 4 anos & 36 & $20 \%$ & $47 \%$ \\
Até 8 anos & 52 & $29 \%$ & $76 \%$ \\
Até 16 anos & 32 & $18 \%$ & $94 \%$ \\
Mais de 16 anos & 10 & $6 \%$ & $100 \%$ \\
& 177 & $100 \%$ & \\
\hline
\end{tabular}

Fonte: dados primários da pesquisa.

TABELA 4

País de origem dos respondentes

\begin{tabular}{l|r}
\hline País & $\%$ \\
\hline EUA & $74,7 \%$ \\
Brasil & $17,1 \%$ \\
Canadá & $2,7 \%$ \\
Outros (Colômbia, Bélgica, África do Sul, Lituânia, & \\
Alemanha, Rússia, Ucrânia, Itália) & $5,6 \%$ \\
Total & $100,0 \%$ \\
\hline
\end{tabular}

Fonte: dados primários da pesquisa.

\section{TABELA 5}

\section{Anos de afiliação à SCIP}

\begin{tabular}{l|c|c|c}
\hline Anos de afiliação à SCIP & Freqüência & \% do Total & \% acumulado \\
\hline Até 4 anos & 87 & $54 \%$ & $54 \%$ \\
Até 8 anos & 42 & $26 \%$ & $81 \%$ \\
Até 16 anos & 28 & $18 \%$ & $98 \%$ \\
Mais de 16 anos. & 3 & $2 \%$ & $100 \%$ \\
& 160 & $100 \%$ & \\
\hline
\end{tabular}

Fonte: dados primários da pesquisa. 
possuem uma área de IC já estabelecida há mais de 10 anos, esta situação se inverte, conforme demonstrado no gráfico 5 .

Há evidências, portanto, da influência da área de IC na constante releitura do ambiente externo, propiciando, às empresas que possuem área de IC já madura, a contínua revisão dos processos internos e dos fatores externos levados em consideração na tomada de decisão.

Ao se observar o comportamento dessas variáveis no grupo de organizações que apresentam maior nível de influência dos FCDs (ou seja, as organizações que foram fundadas há mais de 100 anos), percebese que, mesmo neste grupo de empresas, o tempo de existência da área de IC tem relação inversa com a influência dos FCDs no processo decisório, conforme gráfico 6 , a seguir.

\section{CONCLUSÕES E RECOMENDAÇÕES}

Neste artigo, buscamos destacar o papel e a relevância da inteligência competitiva (IC) para o processo decisório da organização. Como ressaltado, a organização tem duas fases cruciais de elevado risco de ocorrência dos pontos cegos. Na primeira, representada pelos anos iniciais da organização, há grande nível de incerteza em relação ao ambiente externo e, na segunda, durante a maturidade, existe elevada convicção a respeito do ambiente.

Em ambos os casos, a inteligência competitiva pode atuar no sentido de minimizar os problemas inerentes de cada momento. No primeiro, a IC pode auxiliar na estruturação das atividades de monitoramento da organização e, com isso, qualificar mais o processo decisório pela redução dos principais pontos de incerteza; no segundo, a IC pode contribuir para o constante questionamento das convicções da organização, bem como na me-
GRÁFICO 4

Influência dos FCDs de acordo com a idade da organização

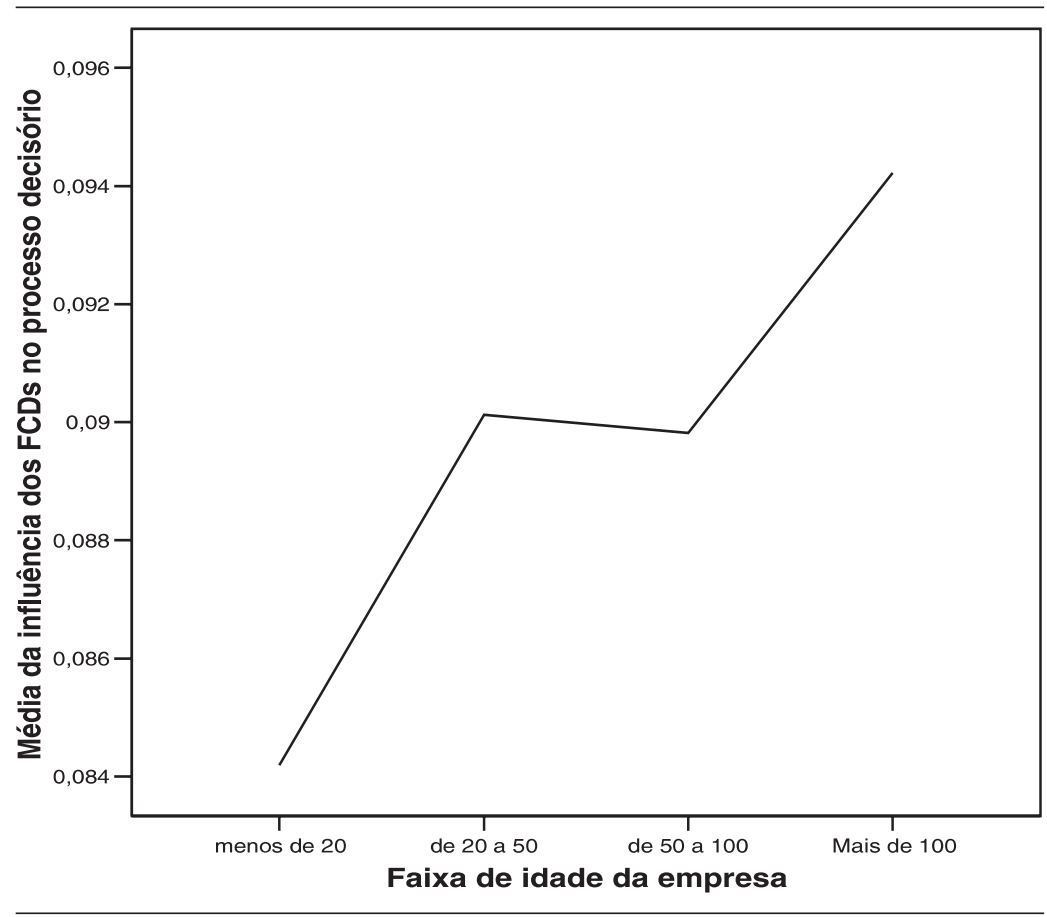

Fonte: dados primários da pesquisa.

\section{GRÁFICO 5}

Comportamento do FCDs, de acordo com a idade da organização, considerando organizações com uma área de IC estabelecida há mais de 10 anos

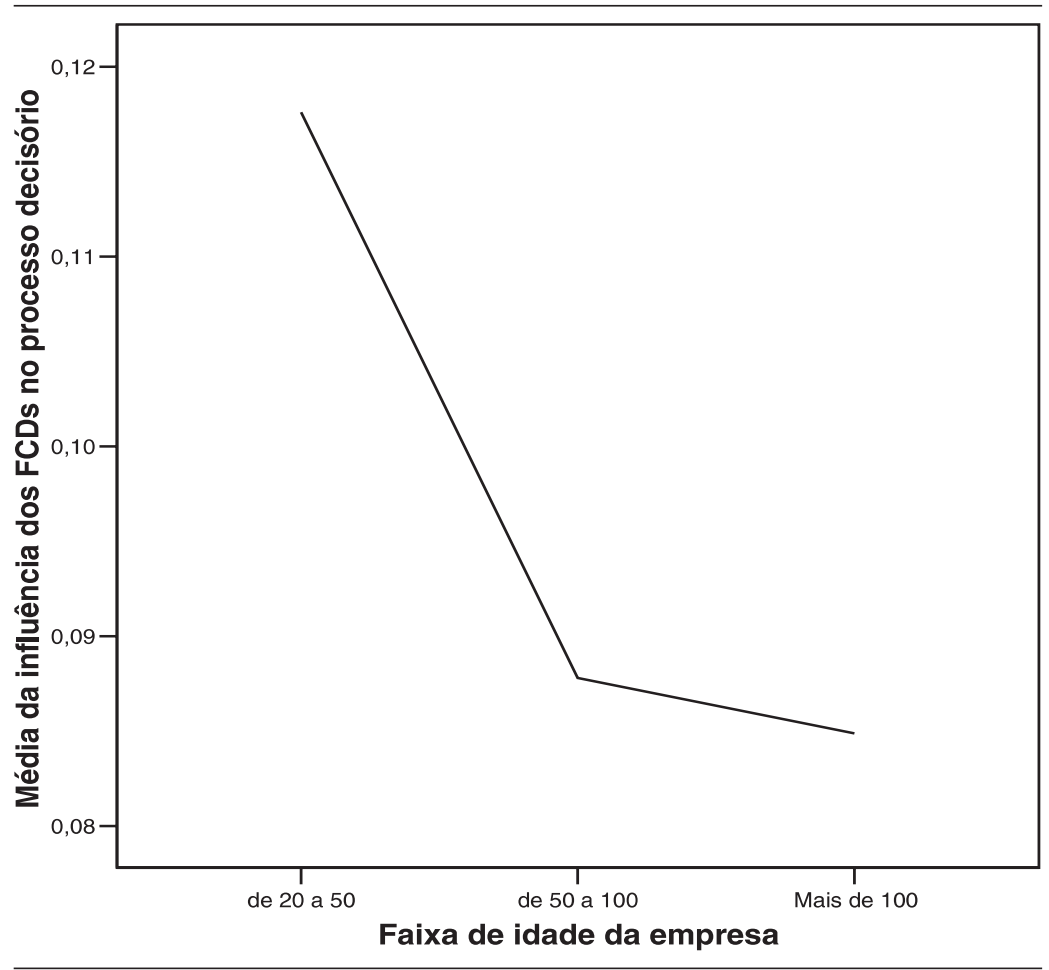

Fonte: dados primários da pesquisa. 
lhoria dos processos utilizados para a percepção e avaliação do ambiente externo.

Para que isto ocorra, a influência da inteligência competitiva no processo decisório deve se contrapor aos fatores cristalizadores das decisões ao longo do desenvolvimento de uma organização. Quando isto se verifica, o risco de a organização apresentar pontos cegos em relação ao ambiente competitivo é bastante reduzido.

Como sugerido no estudo, quanto mais velha uma organização, mais ela tende a ter preponderância dos FCDs no processo decisório, contribuindo para o aumento da ocorrência de pontos cegos. Na pesquisa, isso fica claro quando se separa o grupo de organizações com mais de 100 anos de outros subgrupos, como, por exemplo, organizações fundadas há menos de 20 anos. É visível o papel dos FCDs no processo decisório e, portanto, do risco de ocorrência dos pontos cegos.

Entretanto, mesmo em organizações mais antigas, quando se tomam este grupo e a variável "existência da área de IC", percebese que uma área de IC mais amadurecida reduz a preponderância dos FCDs, mesmo nas organizações mais velhas. Isso, portanto, permite inferir a respeito do papel da IC na redução da influência dos FCDs no processo decisório e, conseqüentemente, na redução dos pontos cegos. Isso ocorreu, ao se compararem os três grupos etários de empresas com aquelas que tinham uma área de IC há pelo menos 10 (dez) anos.

Esse artigo é uma contribuição preliminar para se entender a relação entre a IC e o processo decisório nas organizações, por meio de sua influência sobre os FCDs. Foram tomadas apenas algumas variáveis da pesquisa para a análise do aspecto aqui debatido, ou seja, o papel da IC na redução dos pontos cegos durante o ciclo de vida das organizações. Resultados mais aprofundados serão obtidos a partir da continuação das análises do material da pesquisa.

Em relação ao tópico aqui discutido, para trabalhos futuros, recomenda-se que tal relacionamento seja estudado tomando-se, também, outras variáveis não contempladas neste estudo.

Artigo submetido em 17/11/2005 e aceito em 05/01/2007.

\section{REFERÊNCIAS}

ABREU, Paulo G. F. Definição de um modelo para implantação do Sistema de Captação de Sinais Fracos (SCSF): projeto empresarial. 2000. Monografia (Especialização MBA)- FDC, 2000.

ADIZES, Ichak. Gerenciando os ciclos de vida das organizações. Pearson: Prentice Hall, 2004.

AGUILAR, J. Francis. Scanning the business environment. New York: Macmillian, 1967.

BLANCO, Sylvie; CARON-FASAN, Marie-Laurence; LESCA, Hunbert. Developing capabilities to create collective intelligence within organizations. Journal of Competitive Intelligence and Management, v. 1, n. 1, Spring 2003.

BOUTHILLIER, France; SHEARER, Kathleen. Assessing competitive intelligence software: a guide to evaluating CI technology. Information Today, 2003.

CHANDLER, A. Ensaios para uma teoria histórica da grande empresa. Rio de Janeiro: FGV, 1998.

CYERT, Richard Michael; MARCH, James G. A behavioral theory of the firm. 2nd ed. Oxford: Blackwell Business, 1992.

DAFT, Richard L.; MACINTOSH, Norman B. A tentative exploration into the amount and equivocality of information processing into 
organizational work units. Administrative Science Quarterly, v. 26, n. 2, p. 207-224, 1981.

FULD, Leonard M. Administrando a concorrência. Rio de Janeiro: Editora Record, 1988.

GANESH, Usha; MIREE, Cynthia E.; PRESCOTT, John. Competitive intelligence field research: moving the fiel foward by setting a research agenda. Journal of Competitive Intelligence and Management, v. 1, n. 1, Spring 2003.

GILAD, Benjamin Early Warning. Using competitive intelligence to anticipate market shifts, control risks and create powerful strategies. New York: AMACOM, 2003.

. Industry risk management: CI's next step. Competitive Intelligence Review, v. 4, n. 3, May/June 2001.

HERRING, Jan; FRANCIS, David. Key intelligence topics: a window on the corporate intelligence psyche. Competitive Intelligence Review, $\mathrm{v}$. 10, n. 4, p. 10-19, 1999.

MCGONAGLE, John J. Patterns of development of CI units: the helicon group. Competitive Intelligence Review, Spring 2002.

PRESCOTT, John E. Competitive intelligence: a guide for your journey to best-practice process. Houston: APQC Publications, 2004.
QIU, Tianjiao. Report on 2004 survey results: the effect of entrepreneurial attitude orientation on managerial representations of competitive advantage. Champaign: The University of Illinois, 2004.

SIMON, Herbert A. O comportamento administrativo. Rio de Janeiro: FGV, 1995.

. Theories of decision-making in economics and behavioral science. American Economic Review, v. 49, n. 3, June 1959.

. Administrative behavior: a study of decision-maring process in administrative organizations. 4th ed. New York: The Free Press, 1997.

TYSON, Kirk W. M. Competition in the 21th century. Delray Beach: St. Lucie Press, 1997.

. The complete guide to competitive intelligence. Chicago: Leading Edge Publications, 2002.

VELLA, Carolyn; MCGONAGLE, John. Improved business planning using competitive intelligence. New York: Quorum Books, 1988.

WEIK, Karl. E. The social psychology of organizing. Reading, Mass: Addison Wesley, 1979. 